\title{
Challenges and Opportunities in Electrochemical Technology
}

\author{
Paul R. Shearing * \\ The Electrochemical Innovation Lab, Department of Chemical Engineering, University College London, London, \\ United Kingdom
}

Keywords: electrochemical engineering, energy storage, fuel cells, corrosion, electrochemical reaction engineering, electrochemical deposition, sensors, electrowinning

OPEN ACCESS

Edited and reviewed by: Fengqi You,

Cornell University, United States

*Correspondence:

Paul R. Shearing

p.shearing@ucl.ac.uk

Specialty section:

This article was submitted to Electrochemical Engineering,

a section of the journal

Frontiers in Chemical Engineering

Received: 28 August 2020

Accepted: 02 September 2020

Published: 14 October 2020

Citation:

Shearing PR (2020) Challenges and Opportunities in Electrochemical Technology.

Front. Chem. Eng. 2:599973. doi: 10.3389/fceng.2020.599973
As we approach 50 years since Carl Wagner's 1962 treatise on “The Scope of Electrochemical Engineering" (Wagner, 1962), numerous authors have reflected on the history, status, and perspective of the discipline (Wendt and Kreysa, 1999; Bebelis et al., 2013; Walsh, 2019). Indeed in a recent perspective Prof. Mark E. Orazem paused to reflect on the question "What do electrochemical engineers do?" (Orazem, 2020). This milestone provides an opportunity to reflect on and celebrate the extensive influence of electrochemical engineering in modern society and consider both the breadth and depth of the discipline. Electrochemical engineers have had profound impact on areas spanning commodity chemical production, corrosion, catalysis and energy conversion, and storage. Moreover, the constantly evolving shape of the discipline requires constant evaluation of the growing influence and impact of electrochemical science and technology.

At its heart, the fundamental principles of electrochemical engineering remain the confluence of electrochemical reaction and mass transport phenomena. Beyond the scope of regular "reaction engineering" an electrochemical engineer must consider the interplay of current and voltage in addition to the wider considerations of kinetic, thermodynamic, and transport processes. This basic understanding informs a framework that can be applied to a broad range of materials and devices from micro-batteries to large scale aluminum production facilities, spanning micro-watt to mega-watt scales. Prof. Frank Walsh writes in his seminal text on the subject that "Electrochemical Engineering involves the design, characterization and operation of components, devices and processes which involve the interconversion of chemical and electrical energy" (Walsh, 1993). This elegant description encapsulates the discipline, although its brevity belies the many avenues of endeavor to which the electrochemical engineer has contributed.

A hallmark of the field is its multi-disciplinarity, not only bringing together electrochemists and chemical engineers, but also routinely engaging materials scientists, chemists, physicists, and electrical engineers. As a wider discipline, chemical engineering is under-going a re-birth; central to this is the theme of multi-disciplinarity. The days where undergraduate chemical engineers would default to careers in the oil and gas or process industries have gone, and there is growing recognition of the role of chemical engineers across a range of sectors, and in particular their key role in meeting aggressive targets for decarbonization.

It is highly appropriate that an ambitious and forward-looking journal such as Frontiers in Chemical Engineering embrace these changes and reflect the zeitgeist of our evolving discipline. "Chemical engineering ... offers unparalleled opportunities to address grand challenges facing society" and electrochemical engineering is at the vanguard of this. It is therefore with great pleasure that we are launching a specialty section on Electrochemical Engineering to complement the growing list of themes of the wider journal family. 
The section will encompass a breadth of electrochemical engineering themes, as outlined in the scope; these include, but are not limited to:

- Energy storage

- Energy conversion including fuel cells

- Membrane technologies and water purification

- Corrosion

- Electrochemical reaction engineering

- Electrochemical reactors: current distribution, fluid flow, mass transfer, and kinetics

- Electrochemical deposition

- Modeling electrochemical processes

- Electro-catalytic processes and photoelectrochemical processes

- Membranes: electrochemical processes, water purification

- Electrochemical synthesis and Electrowinning

- Electrochemical Sensors

These themes embody the cornerstones of transport phenomena, current distribution, kinetics, and thermodynamics central to electrochemical engineering. Whilst other outlets for work of this nature exist in isolation, we intend to provide a forum to consolidate and promote electrochemical engineering approaches which can be often overlooked.

\section{REFERENCES}

Bebelis, S., Bouzek, K., Cornell, A., Ferreira, M. G. S., Kelsall, G. H., Lapicque, F., et al. (2013). Highlights during the development of electrochemical engineering. Chem. Eng. Res. Des. 91, 1998-2020. doi: 10.1016/j.cherd.2013.08.029

Orazem, M. E. (2020). Editorial overview: if chemists make chemicals and chemical engineers make money, what do electrochemical engineers do? Curr. Opin. Electrochem. 20, A2-A4. doi: 10.1016/j.coelec.2020.06.008

Wagner, C. (1962). The scope of electrochemical engineering. Adv. Electrochem. Electrochem. Eng. 2, 1-14.

Walsh, F. C. (1993). A First Course in Electrochemical Engineering. Hampshire: Electrochemical Consultancy.

Walsh, F. C. (2019). "Editorial overview electrochemical materials and engineering: directions in electrochemical engineering". Curr. Opin. Electrochem. 16, A1-A3. doi: 10.1016/j.coelec.2019.08.002
Our ambition for the growing editorial board is to reflect the diversity of the electrochemical engineering community in every sense. We seek to provide a forum to champion electrochemical engineering, to provide a rigorous, peerreviewed outlet for cutting edge research that embraces the openaccess philosophy of the Frontiers journal family, and to provide thought leadership for the community through review and perspective articles.

Led by our editorial board, thematic collections will be central to this ambition, and will provide a focal point for deeper investigations of specific technology spaces; however, as we aim to be a voice for the community, we welcome all contributions within the journal scope, and indeed encourage feedback from our readership to guide and finesse the shape of the journal to best reflect the current state-of-the art. On behalf of the editorial board, it is my great pleasure to start the journey in establishing the Electrochemical Engineering section and I look forward to welcoming your contributions.

\section{AUTHOR CONTRIBUTIONS}

The author confirms being the sole contributor of this work and has approved it for publication.

Wendt, H., and Kreysa, G. (1999). Electrochemical Engineering: Science and Technology in Chemical and Other Industries. Berlin; Heidelberg: SpringerVerlag.

Conflict of Interest: The author declares that the research was conducted in the absence of any commercial or financial relationships that could be construed as a potential conflict of interest.

Copyright (c) 2020 Shearing. This is an open-access article distributed under the terms of the Creative Commons Attribution License (CC BY). The use, distribution or reproduction in other forums is permitted, provided the original author(s) and the copyright owner(s) are credited and that the original publication in this journal is cited, in accordance with accepted academic practice. No use, distribution or reproduction is permitted which does not comply with these terms. 